Portland State University

PDXScholar

8-17-2017

\title{
On Finding a Simulation Model for Carbon Nanotubes as Through-Silicon-Vias
}

Alec Wiese

Portland State University

Follow this and additional works at: https://pdxscholar.library.pdx.edu/honorstheses

Let us know how access to this document benefits you.

\section{Recommended Citation}

Wiese, Alec, "On Finding a Simulation Model for Carbon Nanotubes as Through-Silicon-Vias" (2017). University Honors Theses. Paper 471.

https://doi.org/10.15760/honors.471

This Thesis is brought to you for free and open access. It has been accepted for inclusion in University Honors Theses by an authorized administrator of PDXScholar. Please contact us if we can make this document more accessible: pdxscholar@pdx.edu. 
On Finding a Simulation Model for Carbon Nanotubes as Through-Silicon-Vias

by

Alec Wiese

An undergraduate honors thesis submitted in partial fulfillment of the requirements for the degree of

Bachelor of Science

in

University Honors

and

Electrical Engineering

Thesis Adviser

Dr. James Morris

Portland State University 


\section{Abstract:}

This paper outlines the electrical and thermal properties of carbon nanotubes (CNT) as a potential replacement for Copper (Cu) in through silicon vias (TSV). Cu has undesirable thermal properties, and CNTs could resolve issues that high density interconnects experience under high thermal loads around $100 \mathrm{C}$. Most notably, the coefficient of thermal expansion for CNTs is two orders of magnitude lesser than $\mathrm{Cu}$ [1]. The electrical and mechanical properties of CNTs under a high frequency load of $1 \mathrm{THz}$, and high thermal load of $100 \mathrm{C}$ are simulated with ABAQUS 6.16. There is no observable skin effect modelled for the $\mathrm{Cu}$ or Single-Walled Carbon Nanotube (SWCNT) wires simulated in this paper.

\section{Introduction:}

Digital ICs (integrated circuits) are very common in electronics, as well as solid state drives (i.e. flash memory), and the ever-increasing demand for faster, cheaper, and more dense electronics drives for more innovative solutions. Transistors, as the building blocks of electronics, follow Moore's law and become 2X smaller and smaller approximately every two years, which allows electronics to continue to decrease in the surface area they take up. To reduce interconnect length and increase speed, a rather practical solution is to stack chips on top of each other. This allows us to use the third dimension, and interconnect devices with Through Silicon Vias (TSV) and allow for high speed/low latency connections while avoiding extra PCB costs. When chips are stacked on top of each other, the usual materials in vias, like copper, expand and contract due to thermal stress. This is due to thermal stress and the Coefficient of Thermal Expansion (CTE) for different materials [1]. A larger CTE means that a material has a higher tendency to expand due to an increase in temperature. Copper has a very high conductivity and is the most common conductor used in electronics [2] due to its low cost. When a TSV such as Cu has a larger CTE than the Si it is surrounded by, it will expand and extrude during a heat cycle (see Figure 2.1). Because of the differences in the CTE of Cu and Si, the $\mathrm{Cu}$ will experience radial pressure and as a will tend to extrude out of the TSV during increased heat. Once the TSV cools down, the Cu contracts disproportionately to the Si and a gap can form between them. This can reduce performance by deforming the TSV structure and increasing resistance. 


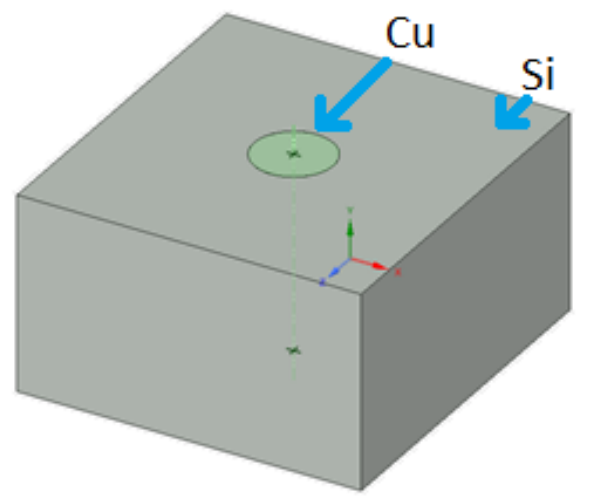

Before Heat Cycle

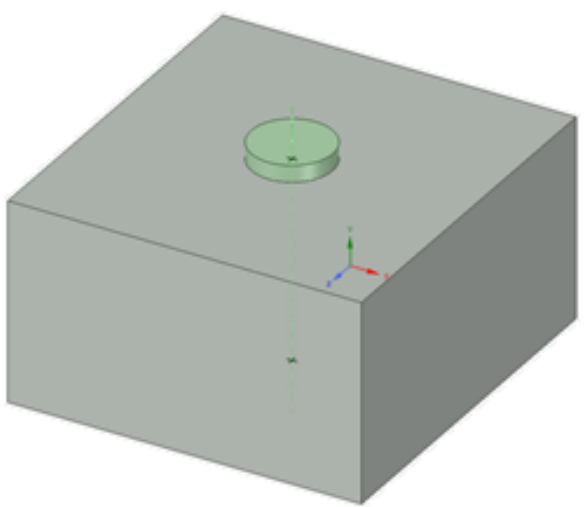

Increased Heat

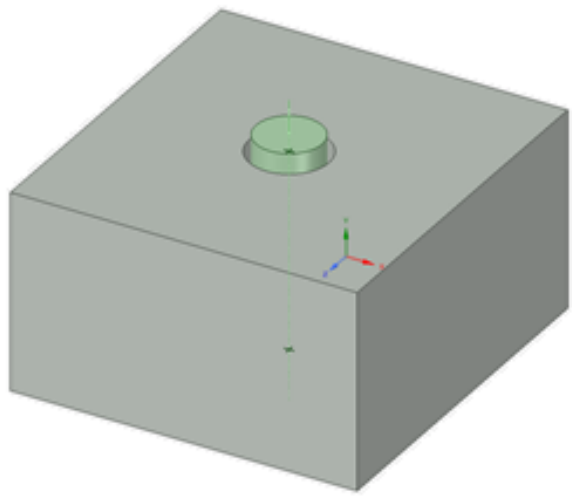

After Cool Down

Figure 2.1 Demonstration of the behavior of Cu as a TSV under a thermal load (Created with ANSYS AIM 18.1 Student Edition)

A solution to this is to use carbon nanotubes (CNT) or CNT-Metal composite TSVs that can result in very similar CTE to that of silicon, mitigating the effects seen with $\mathrm{Cu}$ [2]. CNTs also resolve some of the other issues with $\mathrm{Cu}$ such as electromigration [2]. Over time, electromigration can cause reliability issues and disconnect $\mathrm{Cu}$ TSV s due to the movement of $\mathrm{Cu}$ atoms. Therefore, it is of great interest to investigate how to take advantage of CNT or CNT composite TSVs. This encourages us to use some other material with better thermal properties, however we need to use something conductive to carry our signal. In a bundle, SWCNTs are statistically $1 / 3$ metallic and $2 / 3$ semiconducting so we must assume an average resistivity for a bundle [3]. CNTs have great thermal properties, such as a very low coefficient of thermal expansion [3].

One interesting note is that for interconnects on the nanometer scale, CNTs can provide the possibility for ballistic transport, where the mean free path of an electron is greater than the length of a via. The mean free path of an electron in a Single-Walled Carbon Nanotube is determined by:

$$
l_{m f p}=D\left[k_{1}+k_{2} T+k_{3} T^{2}\right]^{-1}
$$

Where $\mathrm{D}$ is the diameter of the CNT and $k_{1}=3.01 \cdot 10^{-3}, k_{2}=-2.12 \cdot 10^{-5} K^{-1}, k_{3}=4.7$. $10^{-8} \mathrm{~K}^{-2}$. For a diameter of $4 \mathrm{~nm}$ we see mean free paths of $5.52 \mu \mathrm{m}$ at $273 \mathrm{~K}(\sim 0 \mathrm{C})$ and 2.44 $\mu \mathrm{m}$ at $373 \mathrm{~K}(\sim 100 \mathrm{C})$. 


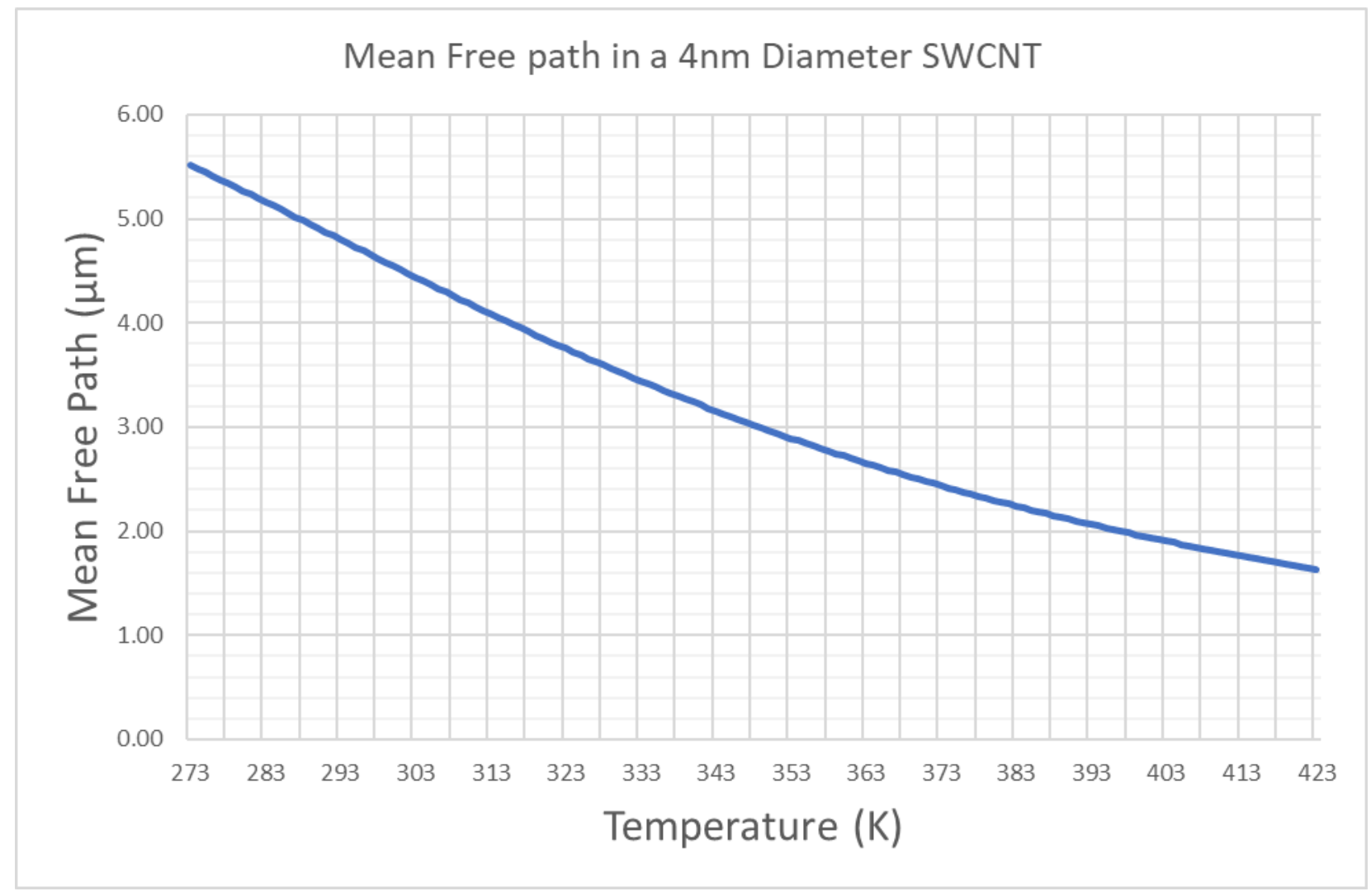

Figure 2.2

The mean free path of $\mathrm{Cu}$ is $39.9 \mathrm{~nm}$ at room temperature (assumed to be $293 \mathrm{k}$ ) [5] whereas it is $4.8 \mu \mathrm{m}$ for CNTs with a diameter of $4 \mathrm{~nm}$. The mean free path is roughly 2 orders of magnitude higher than $\mathrm{Cu}$, this means that for very short interconnects CNTs could provide the possibility of near collision-less electron transport. However, contact resistance between the $\mathrm{Cu}$ contacts to the TSV containing the CNTs can still be an issue with a minimum resistance of 6.45 $\mathrm{k} \Omega$ [4]. At $100 \mathrm{C}(373 \mathrm{~K})$ which is the high end for semiconductor operating temperature, the mean free path of CNTs reduces to $2.44 \mu \mathrm{m}$, but is still much greater than that of Copper (which should also decrease with temperature). The mean free path of an electron in a SWCNT scales linearly with the diameter and can be larger for thicker SWCNTs [4].

The goal of this paper is to model the electrical characteristics of SWCNTs compared to $\mathrm{Cu}$ with Finite Element Analysis (FEA) Software. In the next section, material properties for $\mathrm{Cu}$ and SWCNTs are defined based external experimental results with CNT and graphene structures. Next, this data is used in conjunction with ABAQUS, a type of Multiphysics FEA software to analyze the electrical and thermal properties of CNTs compared to Cu. 


\section{Model Setup:}

SWCNT bundles can be fabricated with a maximum aspect ratio of about 300:1 at several hundred micrometers tall, with a bundle diameter of $200 \mu \mathrm{m}$ [2]. Since wafers are typically 20-150 $\mu \mathrm{m}$ thick, we are well within the range of growth for CNTs. Model 1 and Model 2 have been designed with $0.1 \mu \mathrm{m}$ length to achieve the finest mesh possible. A length this short should result in ballistic conduction, as $0.1 \mu \mathrm{m}$ is much shorter than the $l_{m f p}$ of $2.44 \mu \mathrm{m}$ at $373 \mathrm{~K}$. However, since ABAQUS will not consider ballistic conduction, the length is sufficient to show electrical effects for a longer via.

Commonly accepted values were used for $\mathrm{Cu}$ for material properties outlined in Table 3.1. A range of sources was required to get material property values for CNTs, which are specified in Table 3.2 and Table 3.3. Table 3.2 shows the macroscopic properties of CNT bundles, whereas Table 3.3 shows the properties adjusted for a SWCNT with a diameter of 4 $\mathrm{nm}$ and a thickness of $0.335 \mathrm{~nm}$ [6]. This adjustment was done by changing values dependent on volume and surface area. Since the SWCNT properties in Table 3.2 are macroscopic (for bundles) and our ABAQUS model of a SWCNT is hollow, the material properties must be adjusted such that this loss of surface area and volume is accounted for. With a thickness of 0.35 (0.335 $\mathrm{nm}$ from [6] rounded to nearest possible value with ABAQUS), the surface area is $4.013 \mathrm{~nm}^{-2}$ from equation (1). This adjusted surface area is $31.94 \%$ that of a solid wire with the same diameter of $4 \mathrm{~nm}$, so the properties depending on area and volume were multiplied by the reciprocal of 0.3194 (3.131) to account for the hollow shape. E.g. Electrical Conductivity increased from $2.9 \mathrm{~S} / \mu \mathrm{m}$ to $9.08 \mathrm{~S} / \mu \mathrm{m}$ (otherwise the hollow shape would have incorrectly increased resistance for a SWCNT in our model).

$$
\text { Surface area of } 4 \text { nm diameter } C N T=\left[\pi \cdot 2^{2}\right]-\left[\pi \cdot(2-0.35)^{2}\right] \mathrm{nm}^{-2}
$$

SI units of time in seconds s were used, however length and mass units were converted from $\mathrm{SI}$ and are based on $\mu \mathrm{g}, \boldsymbol{\mu m}$ rather than $\mathrm{Kg}$ and $\mathrm{m}$ respectively. This is due to the accuracy handling of ABAQUS. Units were converted because using SI units in ABAQUS resulted in many output values being rounded to zero. 


\begin{tabular}{|c|l|l|l|}
\hline \multirow{4}{*}{$\begin{array}{c}\text { Copper } \\
\text { (Cu) }\end{array}$} & Property & Value & Units \\
\cline { 2 - 4 } & Density & $8.98 \mathrm{E}-06$ & $\mu \mathrm{g} /\left(\mu \mathrm{m}^{\wedge} 3\right)$ \\
\cline { 2 - 4 } & Young's Modulus & $1.2 \mathrm{E}+11$ & {$\left[\mathrm{~N} / \mu \mathrm{m}^{\wedge} 2\right] \mathrm{E}^{\wedge}-12$} \\
\cline { 2 - 4 } & Poisson's Ratio & 0.38 & Ratio \\
\cline { 2 - 4 } & CTE & $1.65 \mathrm{E}-05$ & $\mu \mathrm{m} /(\mu \mathrm{m}-\mathrm{K})$ \\
\cline { 2 - 4 } & Thermal Conductivity & $4 \mathrm{E}+14$ & $\mathrm{~W} /(\mu \mathrm{m}-\mathrm{K}) \mathrm{E}^{\wedge}-18$ \\
\cline { 2 - 4 } & Specific Heat & $3.85 \mathrm{E}+20$ & {$\left[\mathrm{~J} \mathrm{~K} \mathrm{~K}^{\wedge}-1\right] \mathrm{E}^{\wedge}-18$} \\
\cline { 2 - 4 } & Electrical Conductivity & 58 & $\mathrm{~S} / \mu \mathrm{m}$ \\
\cline { 2 - 4 } & Relative Permeability & 1 & Ratio \\
\hline
\end{tabular}

Table 3.1 Material Properties of Copper

\begin{tabular}{|c|c|c|c|c|}
\hline \multirow{9}{*}{$\begin{array}{c}\text { Carbon } \\
\text { Nanotubes } \\
\text { (CNT) }\end{array}$} & Property & Value & Units & Reference \\
\hline & Density & $1.60 \mathrm{E}-06$ & $\mu \mathrm{g} /\left(\mu \mathrm{m}^{\wedge} 3\right)$ & [7] \\
\hline & Young's Modulus & $1 \mathrm{E}+12$ & {$\left[\mathrm{~N} / \mu \mathrm{m}^{\wedge} 2\right] \mathrm{E}^{\wedge}-12$} & \multirow{3}{*}{ [1] } \\
\hline & Poisson's Ratio & 0.17 & Ratio & \\
\hline & CTE & See Table 3.4 & $\mu \mathrm{m} /(\mu \mathrm{m}-\mathrm{K})$ & \\
\hline & Thermal Conductivity & $3.5 \mathrm{E}+15$ & $W /(\mu m-K) E^{\wedge}-18$ & [7] \\
\hline & Specific Heat & $6 \mathrm{E}+20$ & {$\left[\mathrm{~J} \mathrm{~K} \mathrm{~K}^{\wedge}-1\right] \mathrm{E}^{\wedge}-18$} & [8] \\
\hline & Electrical Conductivity & 2.9 & $\mathrm{~S} / \mu \mathrm{m}$ & [9] \\
\hline & Relative Permeability & 1 & Ratio & \\
\hline
\end{tabular}

Table 3.2 Material Properties of SWCNTS

\begin{tabular}{|c|c|c|c|c|}
\hline \multirow{9}{*}{$\begin{array}{c}\text { Carbon } \\
\text { Nanotubes } \\
\text { Hollow (CNT-H) } \\
4 \mathrm{~nm} \text { Diameter }\end{array}$} & Property & Value & Units & Reference \\
\hline & Density & $5.01 \mathrm{E}-06$ & $\mu \mathrm{g} /\left(\mu \mathrm{m}^{\wedge} 3\right)$ & [7] \\
\hline & Young's Modulus & $3.13 E+12$ & {$\left[\mathrm{~N} / \mu \mathrm{m}^{\wedge} 2\right] \mathrm{E}^{\wedge}-12$} & \multirow{3}{*}{ [1] } \\
\hline & Poisson's Ratio & 0.17 & Ratio & \\
\hline & CTE & See Table 3.4 & $\mu \mathrm{m} /(\mu \mathrm{m}-\mathrm{K})$ & \\
\hline & Thermal Conductivity & $1.10 \mathrm{E}+16$ & $W /(\mu m-K) E^{\wedge}-18$ & [7] \\
\hline & Specific Heat & $1.88 \mathrm{E}+21$ & {$\left[J K^{\wedge}-1\right] E^{\wedge}-18$} & [8] \\
\hline & Electrical Conductivity & 9.08 & $\mathrm{~S} / \mu \mathrm{m}$ & [9] \\
\hline & Relative Permeability & 1 & Ratio & \\
\hline
\end{tabular}

Table 3.3 Material Properties of SWCNTS Adjusted for Surface Area in 4nm Diameter SWCNT 


\begin{tabular}{|c|c|c|}
\hline \multicolumn{2}{|c|}{$\begin{array}{l}\text { Coefficient of Thermal Expansion } \\
\text { (CTE) For SWCNTS } \\
\text { (Ratio of expansion to length) }\end{array}$} & \multirow{2}{*}{$\begin{array}{c}\text { Temperature } \\
\text { (K) }\end{array}$} \\
\hline Axial & Radial & \\
\hline 0 & 0 & 0 \\
\hline$-1.70 E-07$ & $-2.50 \mathrm{E}-07$ & 233 \\
\hline$-1.00 \mathrm{E}-07$ & $-2.50 \mathrm{E}-07$ & 298 \\
\hline $2.50 \mathrm{E}-07$ & $1.00 \mathrm{E}-07$ & 398 \\
\hline $1.60 \mathrm{E}-06$ & $1.35 \mathrm{E}-06$ & 600 \\
\hline $3.25 E-06$ & $3.00 \mathrm{E}-06$ & 1200 \\
\hline
\end{tabular}

Table 3.4 Coefficient of Thermal Expansion (CTE) for SWCNTS

Five models were simulated. Models 1-4 used "ABAQUS Standard \& Explicit" with electrical-thermal-structural coupling, while Model 5 used the "ABAQUS Electromagnetic". Model 1 is a Copper nanowire $4 \mathrm{~nm}$ in diameter and $100 \mathrm{~nm}$ long. The model simulates the current distribution and thermal expansion due to $100 \mathrm{C}$ external temperature. Model 2 is a SWCNT $4 \mathrm{~nm}$ in diameter and $100 \mathrm{~nm}$ long, also evaluating the current distribution and thermal expansion due to $100 \mathrm{C}$ external temperature. Model 3 is a bundle of seven SWCNTs evaluating the current distribution in the bundle. Model 4 attempts to model the skin effect of a bundle of 7 SWCNTs at an extremely high frequency (100 PHz). Model 5 attempts to evaluate the magnetic fields of four SWCNTs surrounded by $\mathrm{Cu}$. The boundary conditions are listed for each model in Table 3.5. 


\begin{tabular}{|c|c|c|c|c|}
\hline Model & Boundary Condition & Value & Unit & Location \\
\hline \multirow{4}{*}{$\begin{array}{l}\text { Model 1: Copper wire } 4 \\
\text { nm Diameter - } 100 \mathrm{~nm} \\
\text { long }\end{array}$} & Temperature & 373.15 & $\mathrm{~K}$ & Top \\
\hline & Low Electrical Potential & 0 & $\mathrm{~V}$ & Bottom \\
\hline & Periodic Potential at $1 \mathrm{THz}$ & -1.372 to 1.372 & $\mathrm{~V}$ & Top \\
\hline & Encastre & -- & -- & Top \\
\hline \multirow{4}{*}{$\begin{array}{l}\text { Model 2: SWCNT } 4 \text { nm } \\
\text { Diameter - } 100 \mathrm{~nm} \text { long }\end{array}$} & Temperature & 373.15 & K & Top \\
\hline & Low Electrical Potential & 0 & $\mathrm{~V}$ & Bottom \\
\hline & Periodic Potential at $1 \mathrm{THz}$ & -1.372 to 1.372 & $\mathrm{~V}$ & Top \\
\hline & Encastre & -- & -- & Top \\
\hline \multirow{4}{*}{$\begin{array}{l}\text { Model 3: Cu Via } 50 \mu \mathrm{m} \\
\text { Diameter } 100 \mu \mathrm{m} \text { long }\end{array}$} & Temperature & 373.15 & K & All sides \\
\hline & Low Electrical Potential & 0 & $\mathrm{~V}$ & Bottom \\
\hline & Periodic Potential at $1 \mathrm{THz}$ & -1.372 to 1.372 & V & Top \\
\hline & Encastre & -- & -- & Top \\
\hline \multirow{4}{*}{$\begin{array}{l}\text { Model 4: Bundle of } \\
\text { seven SWCNTs } 4 \mathrm{~nm} \\
\text { Diameter - } 25 \mathrm{~nm} \text { long }\end{array}$} & Temperature & 373.15 & $\mathrm{~K}$ & Top of bundle \\
\hline & Low Electrical Potential & 0 & $\mathrm{~V}$ & Bottom of bundle \\
\hline & Periodic Potential at $100 \mathrm{PHz}$ & -1.372 to 1.372 & $\mathrm{~V}$ & Top of bundle \\
\hline & Contacts and Interaction Properties & \multicolumn{3}{|l|}{ See Appendix A } \\
\hline \multirow{3}{*}{$\begin{array}{c}\text { Model 5: } 4 \mathrm{~nm} \\
\text { Diameter SWCNTs in Cu }\end{array}$} & Low Electrical Potential & 0 & $\mathrm{~V}$ & Bottom \\
\hline & Periodic Potential at $1 \mathrm{THz}$ & -1.372 to 1.372 & $\mathrm{~V}$ & Top end of CNTs \\
\hline & Temperature & 373.15 & K & Whole Model \\
\hline
\end{tabular}

Table 3.5 Boundary Conditions for Models 1-5

The encastre is boundary condition in ABAQUS that indicates the surface is fixed to that location [10]. The encastre was used in Model 1, Model 2, and Model 3 to prevent any rotation or movement from occurring that may interfere with the displacement calculations. The encastre was not needed in Model 4 and Model 5 because there were no thermal or mechanical interactions occurring that caused displacement.

In ABAQUS, a "Time Period" is specified for each model. This "Time Period" was chosen to be long enough such that each model could at least reach a steady thermal and mechanical state before terminating. Sometimes models were manually terminated later than others, and so the reported "Total Time" is insignificant and is not included in all models. Minimum and maximum time increments are specified and ABAQUS automatically determines values in this range for each increment to ensure model convergence. Time increments for each increment are reported as "Step Time" in each model and tend to be smaller at the beginning of the simulation where changes in displacement and temperature are the greatest. Near the end of the simulation these step sizes tend to become larger. For the models where we observe 
displacement and temperature, at least two increments were observed where the maximum displacement and temperature had not changed, and the final increment was reported. The "Step Time" is also insignificant for these models. The "Time Period" and "Step Time" appear in Models 1-4.

The "Time-Harmonic" frequency for the electromagnetic model is set in Model 5 as a range from 0 to $1 \mathrm{THz}$ (input as rad/s). This is in place of the "Time Period" from Models 1-4. The total time is equivalent to the frequency value in each increment in ABAQUS Electromagnetic models. It is unclear if the Frequency value has any effect.

The "Deformation Scale Factor" given in the model figures is set by ABAQUS and is the ratio to 1 in which the deformation of the model is shown [11]. This is to aid visualization of displacement deformation by exaggerating (when "Deformation Scale Factor" is greater than 1) the deformation extent. This has no effect on the results, only the shape of the model in the viewer. The Deformation Scale Factor is displayed in each model screenshot in Section 4. Since the desired information is the absolute displacement, the "Deformation Scale Factor" is also insignificant for our model, except as a visual aid. 


\section{Results:}

\subsection{Model 1: Cu 4nm Diameter}

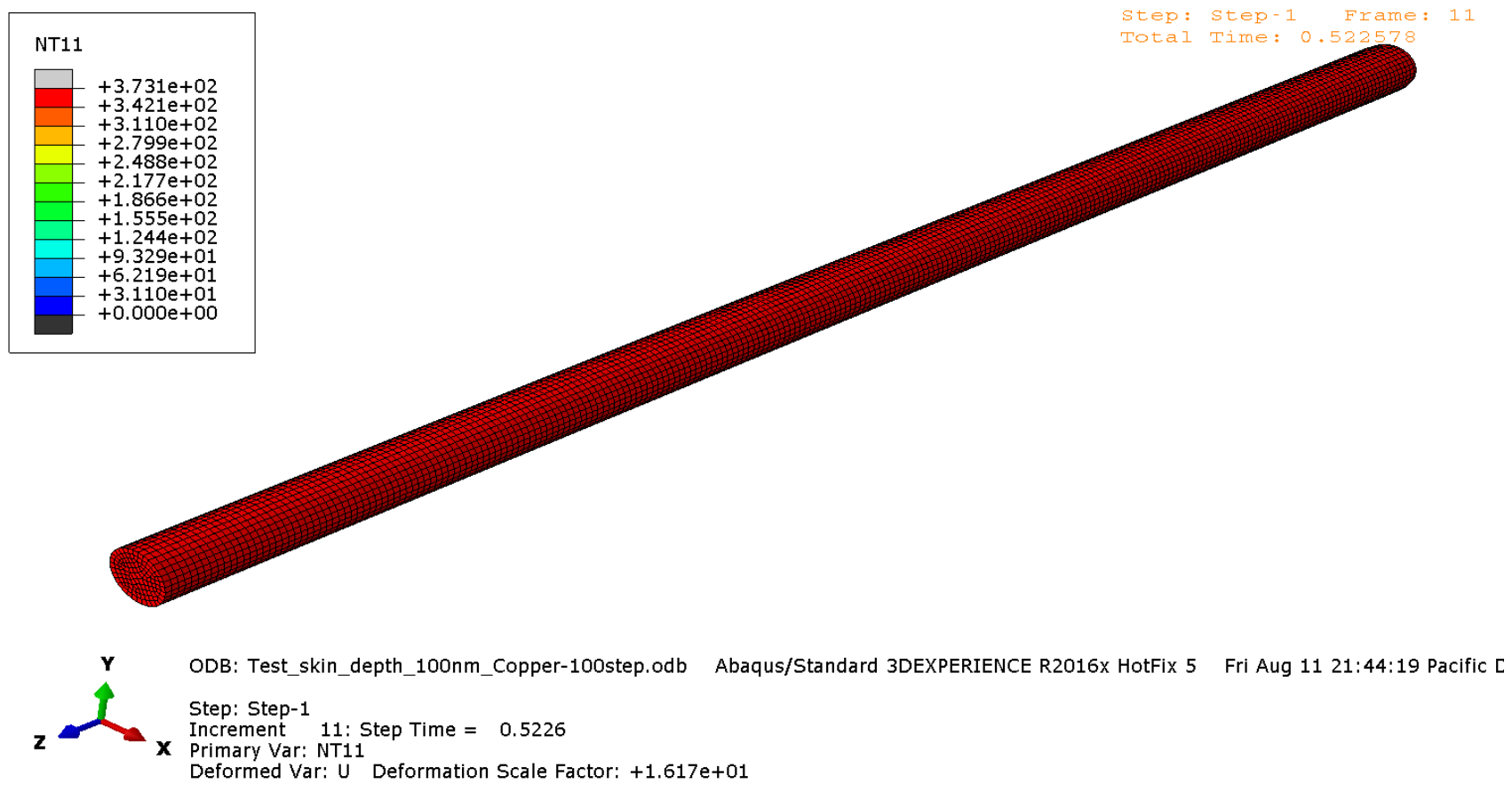

Figure 4.1.1

\section{Variable NT11 is Temperature in Kelvin}

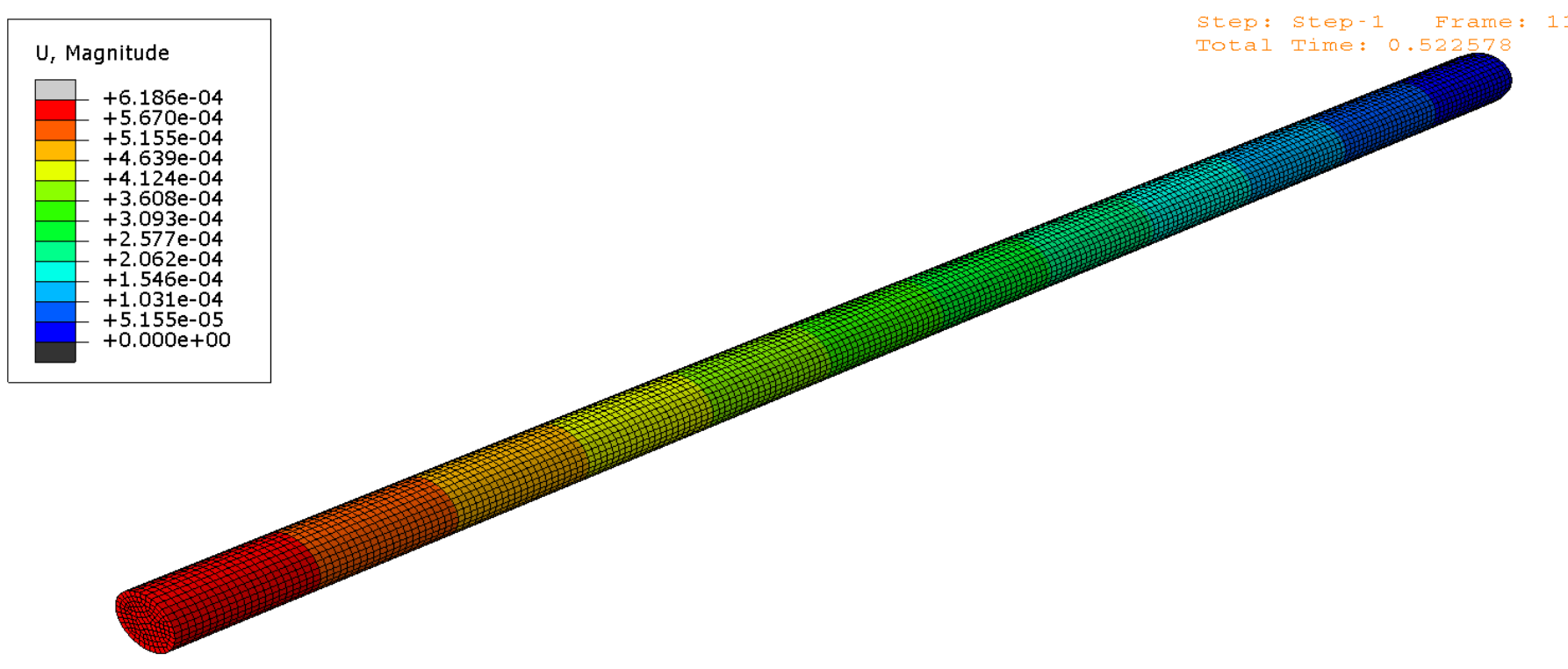

Figure 4.1.2 


\subsection{Model 2: SWCNT 4nm Diameter}

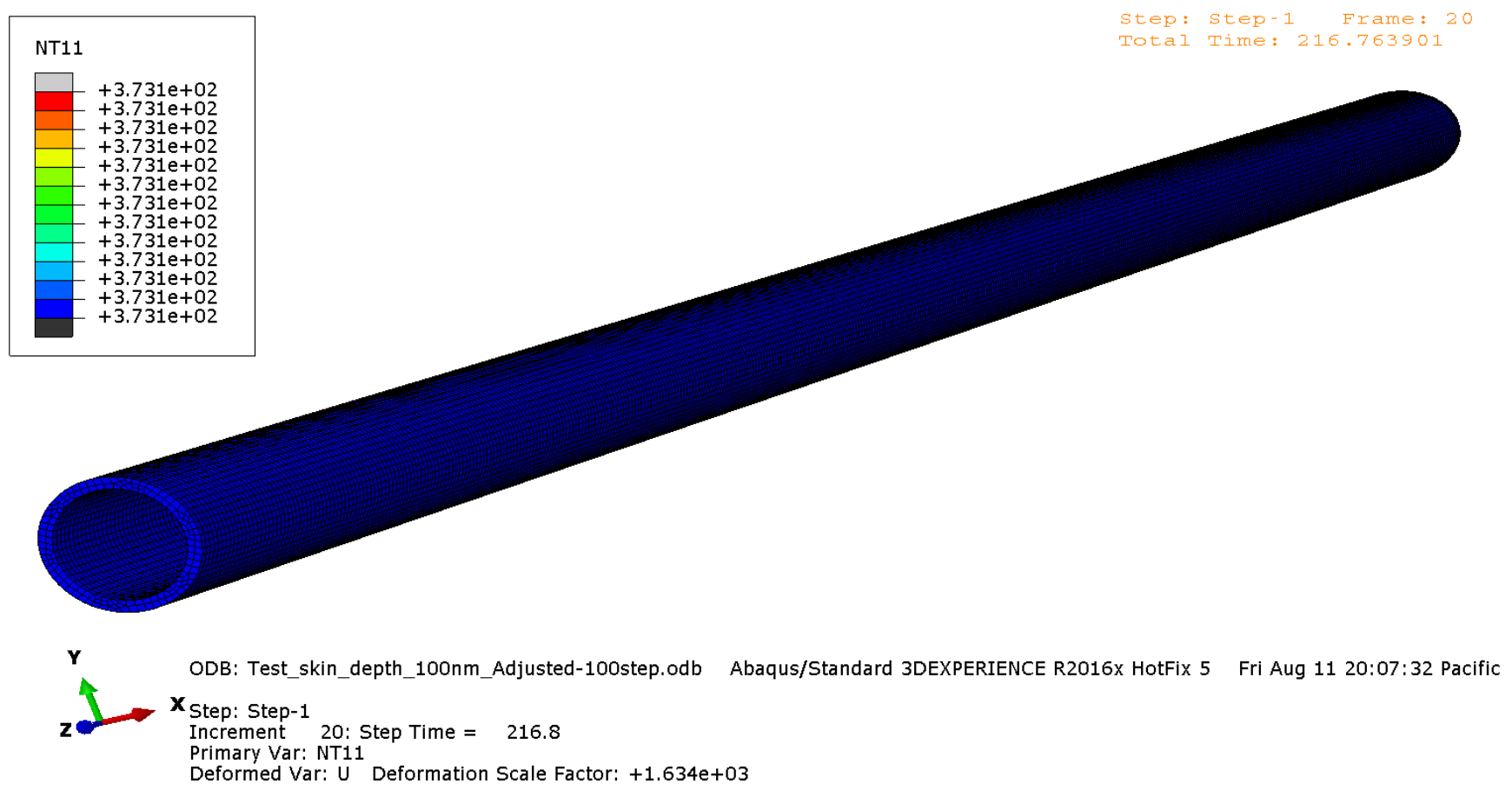

Figure 4.2.1

\section{Variable NT11 is Temperature in Kelvin}

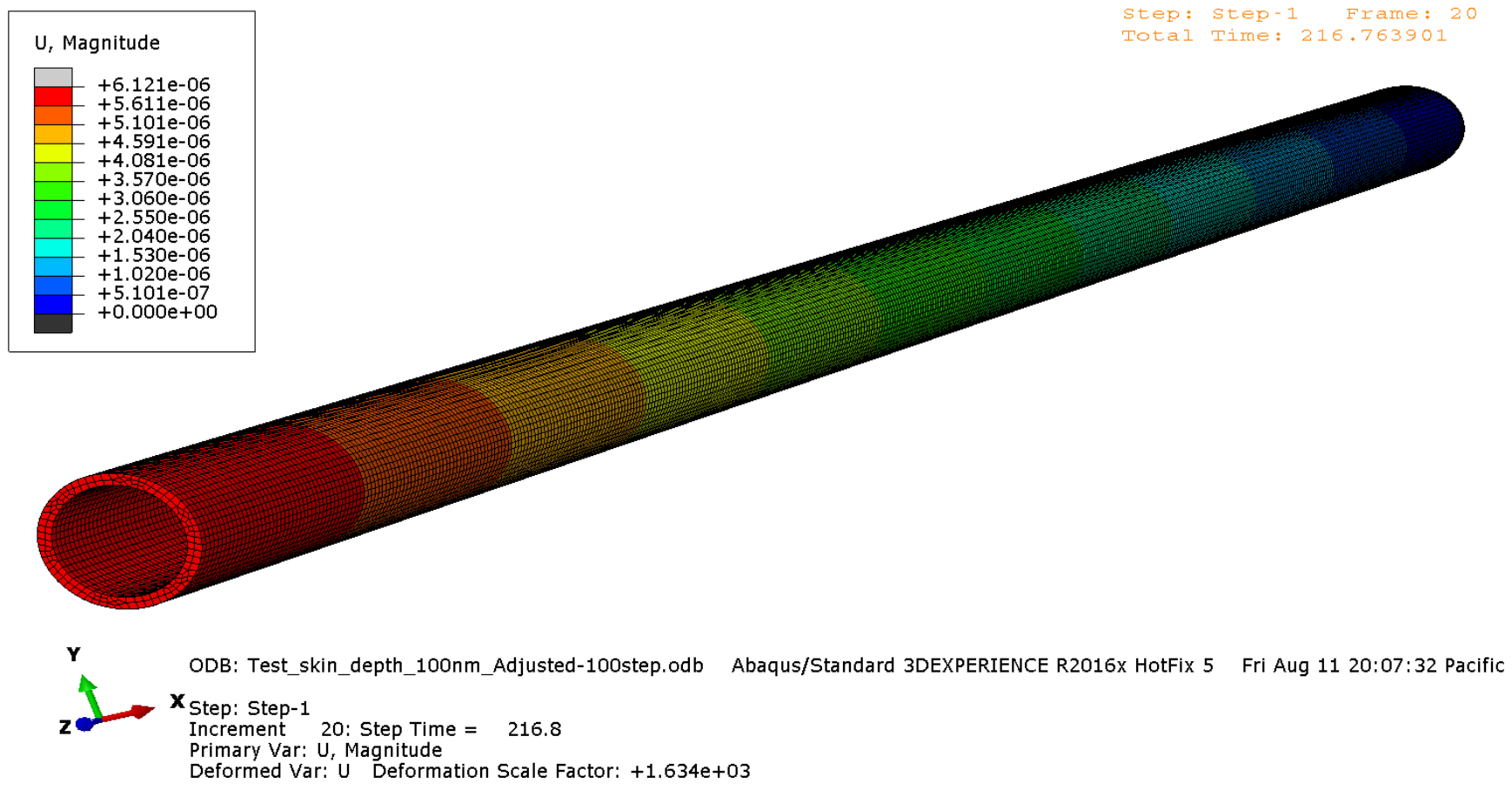

Figure 4.2.2 


\subsection{Model 3: Cu Via $50 \mu \mathrm{m}$ Diameter, $100 \mu \mathrm{m}$ Length}
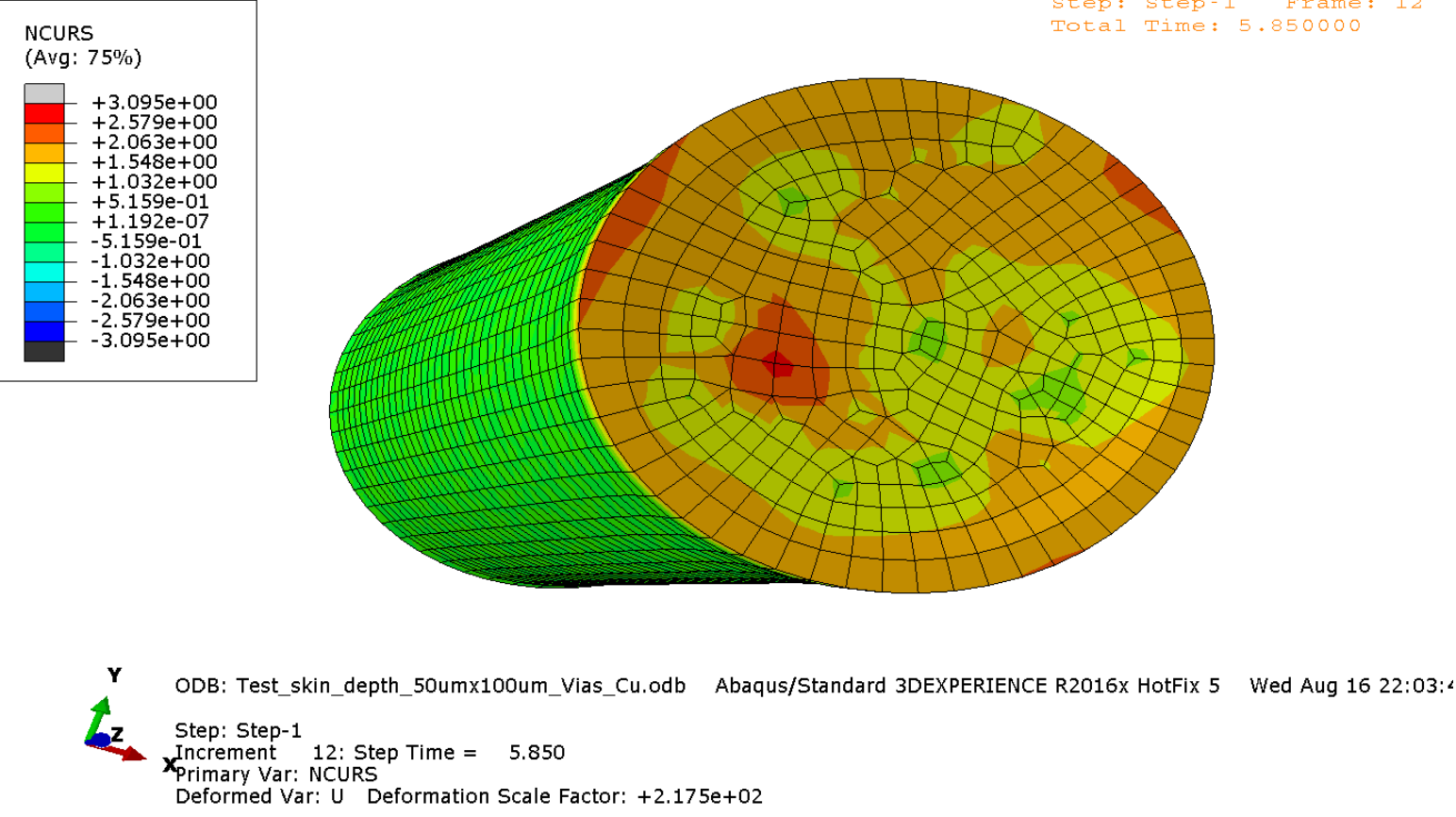

Figure 4.3.1

\section{Variable NCURS is current in A}
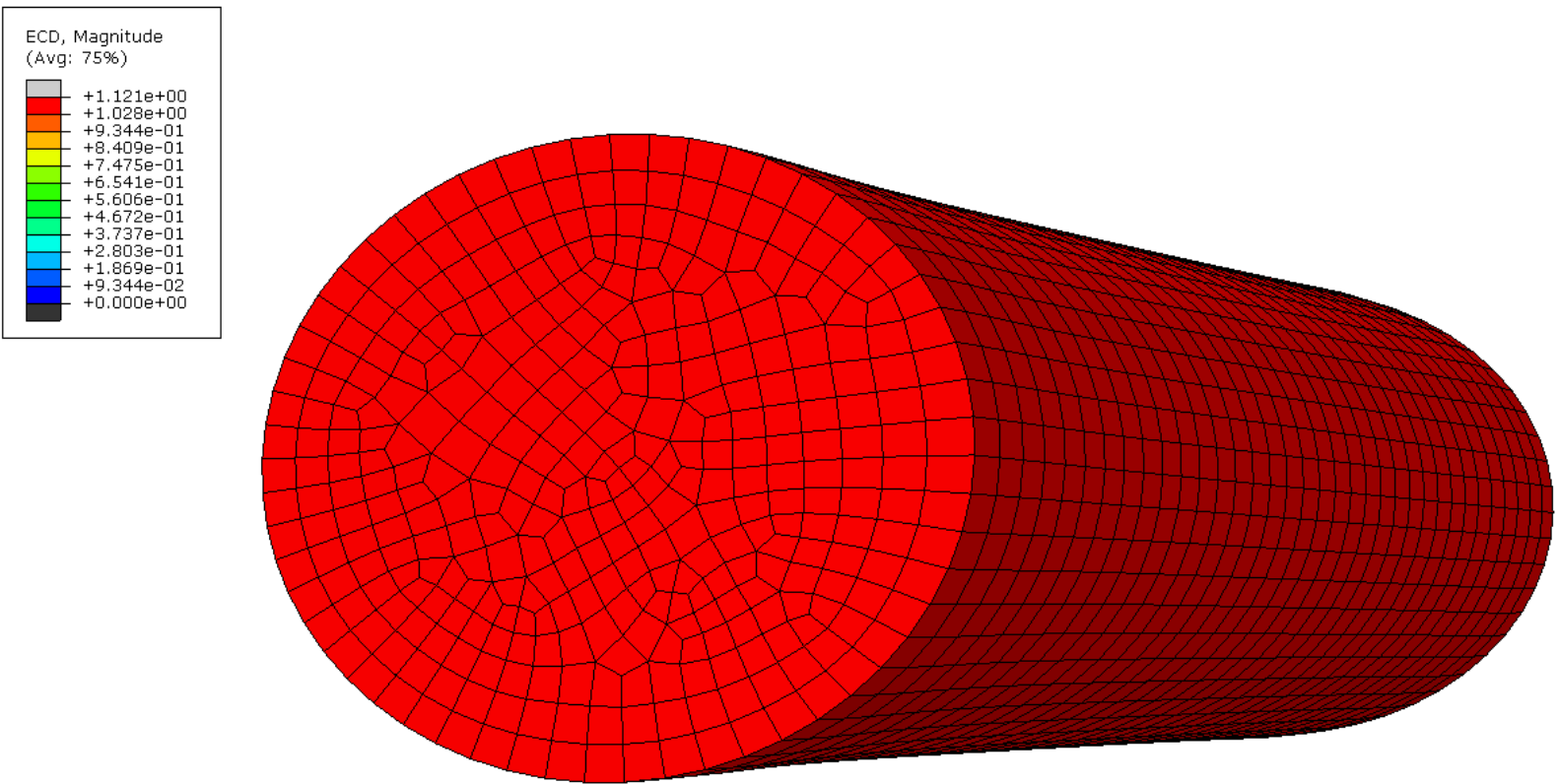

ODB: Test_skin_depth_50um×100um_Vias_Cu.odb Abaqus/Standard 3DEXPERIENCE R2016x HotFix 5 Wed Aug 16 22:03:43 Pacific Daylight Time 2017

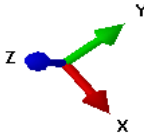

Step: Step-1

Increment 20: Step Time $=165.4$

Deformed Var: U Deformation Scale Factor: $+9.948 e+01$

Figure 4.3.2

Variable ECD is in $A \mu m^{-2}$ 


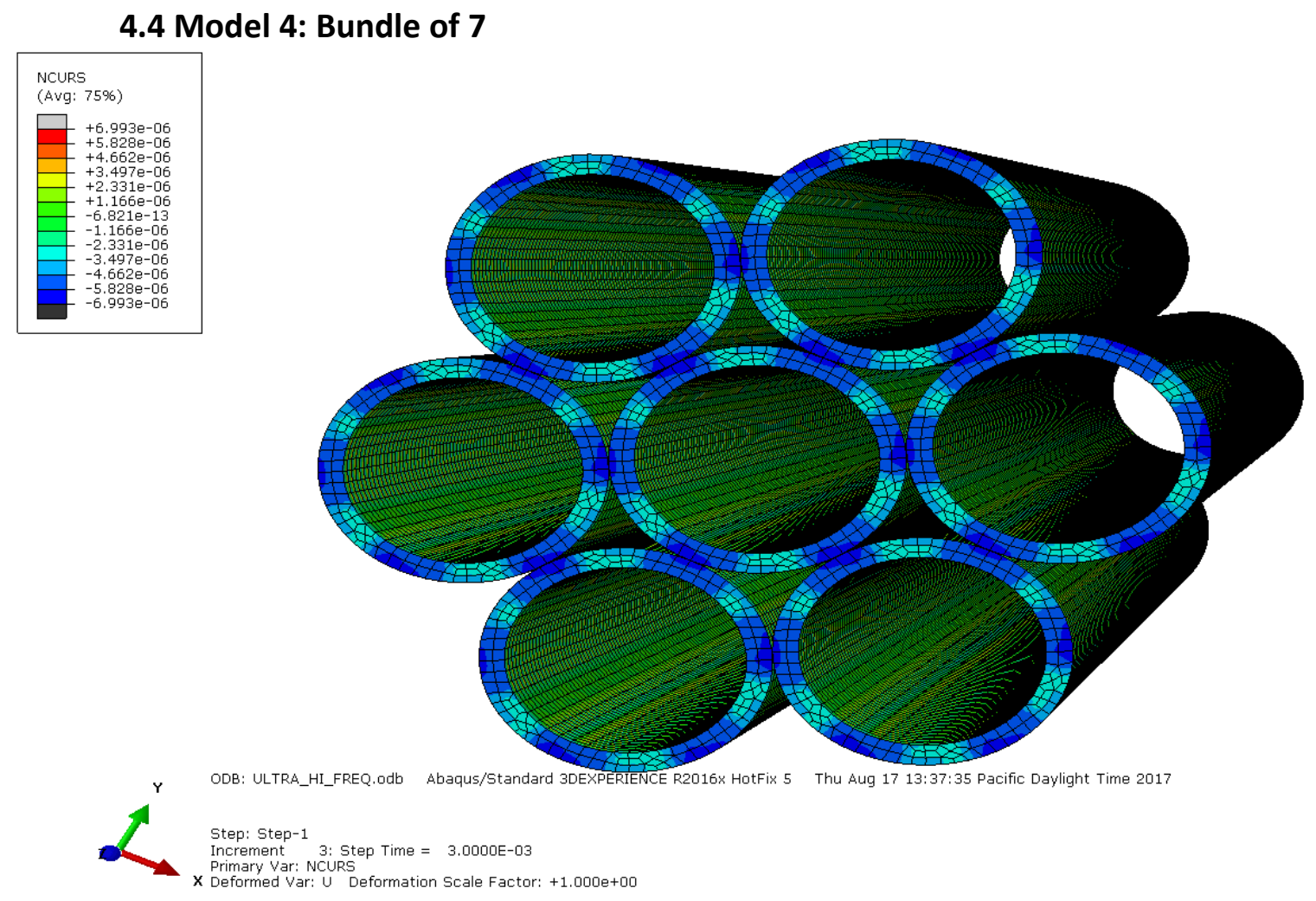

Figure 4.4.1

Variable NCURS is current in A
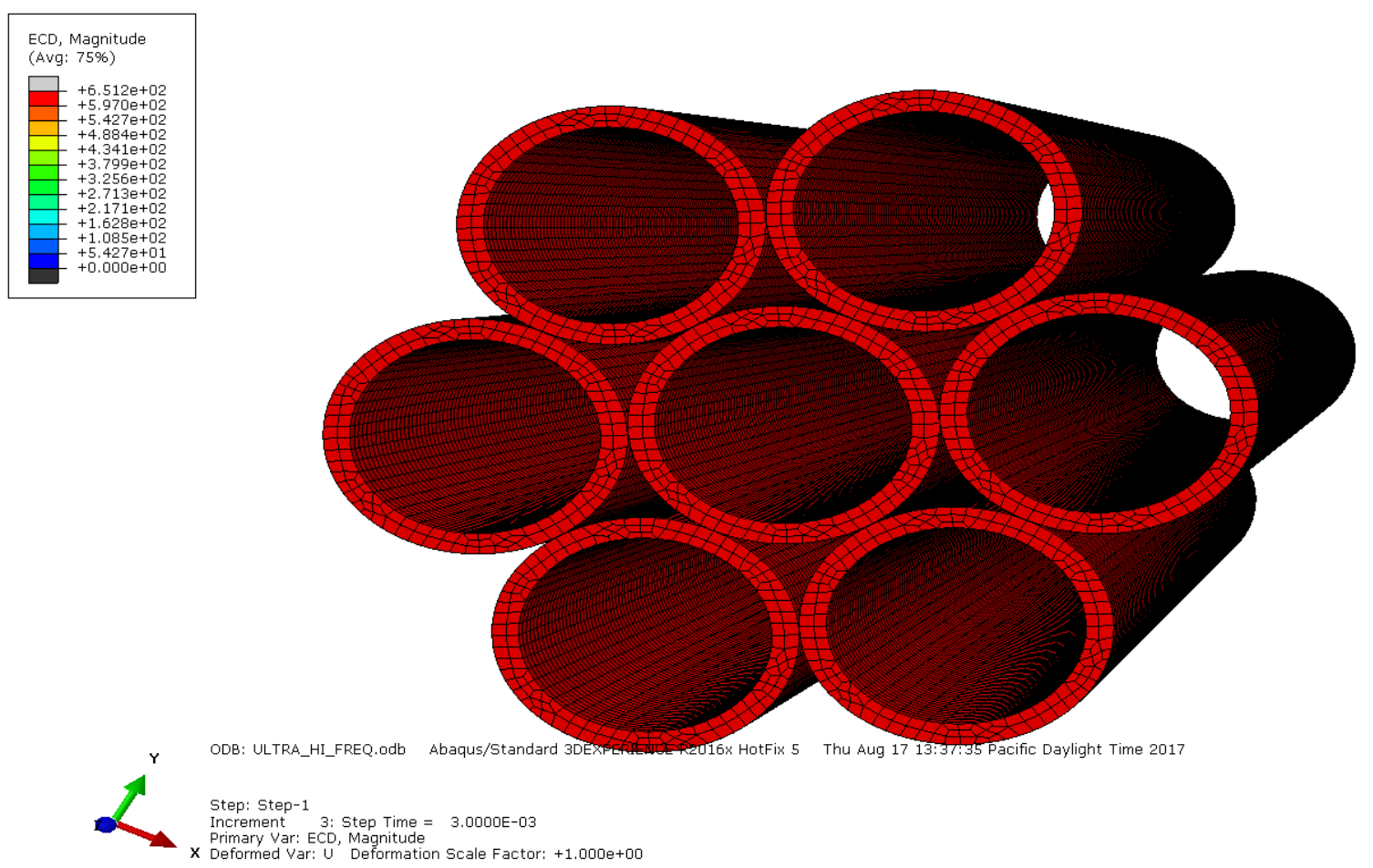

Figure 4.4.2

Variable ECD is in A $\mu \mathrm{m}^{-2}$ 
4.5 Model 5: Four SWCNTs of $4 \mathrm{~nm}$ Diameter in $\mathrm{Cu}$

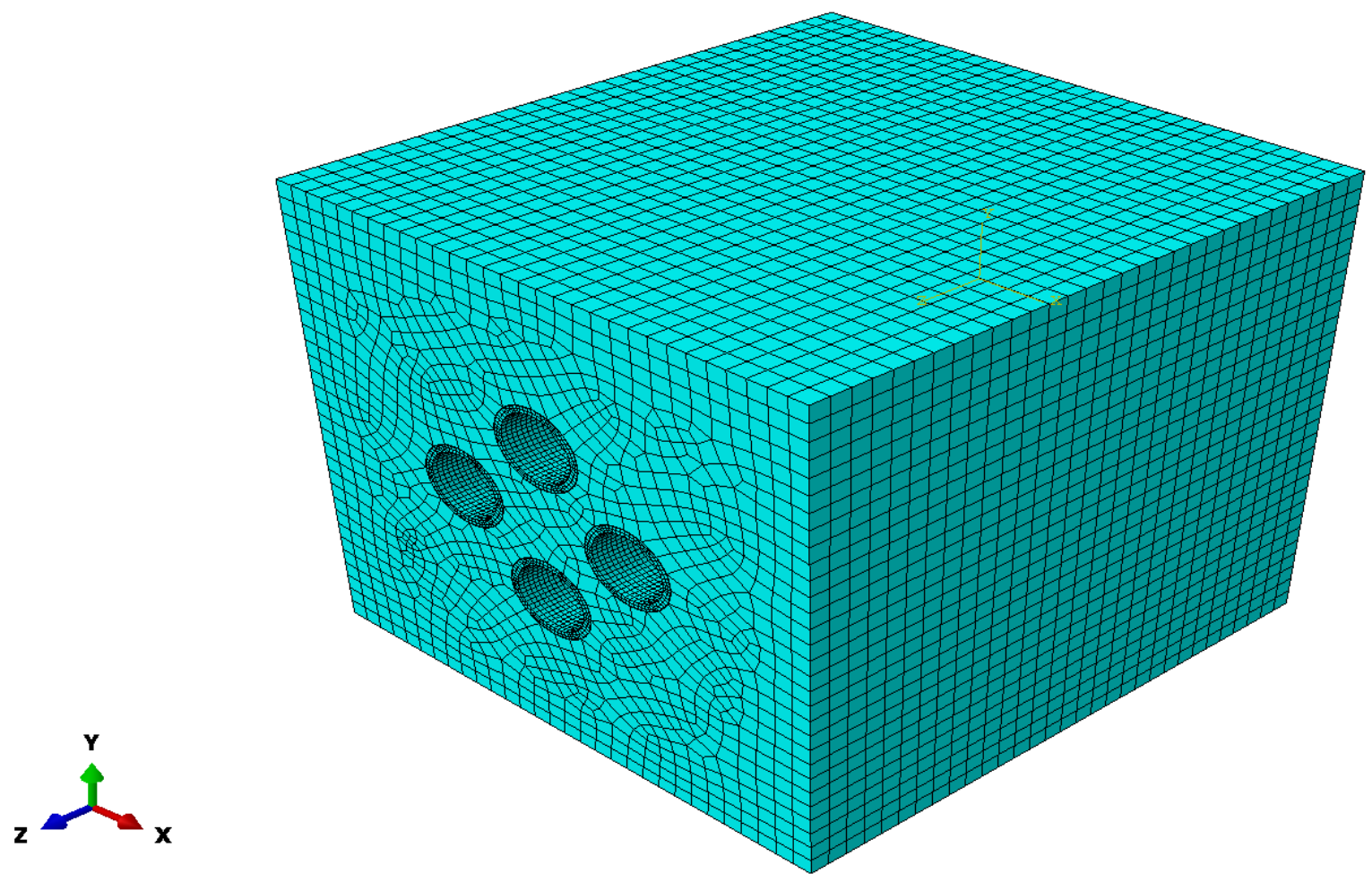

Figure 4.5.1

View of the structure for orientation reference
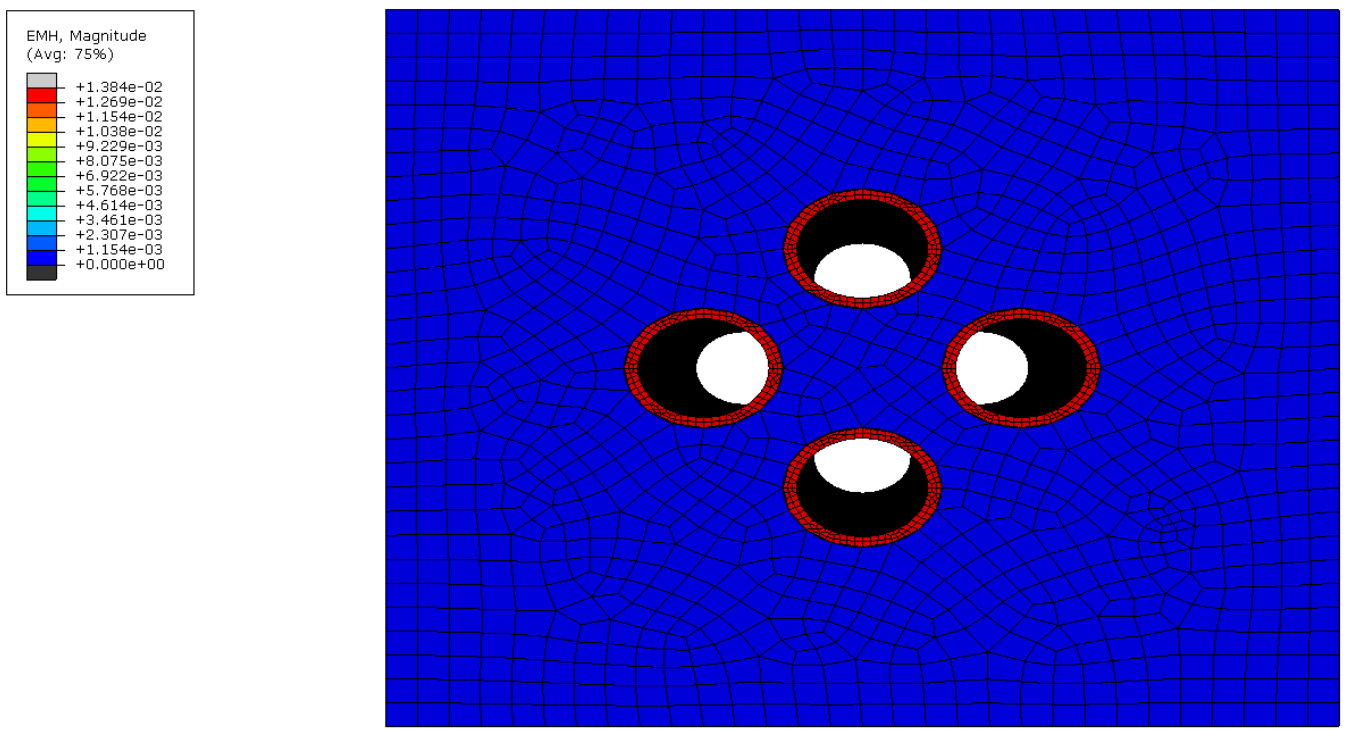

$\times \leftarrow$

ODB: EMAGTEST5.odb

Abaqus/Standard 3DEXPERIENCE R2016x HotFix 5 Thu Aug 17 08:24:21 Pacific Daylight Time 2017

Step: Step-1
Increment

Primary Var: EMH, Magnitude Complext Re

Figure 4.5.2

Variable EMH is Magnetic Field in $\mathrm{A} \mathrm{m}^{-1} \mathrm{E}+6$ 


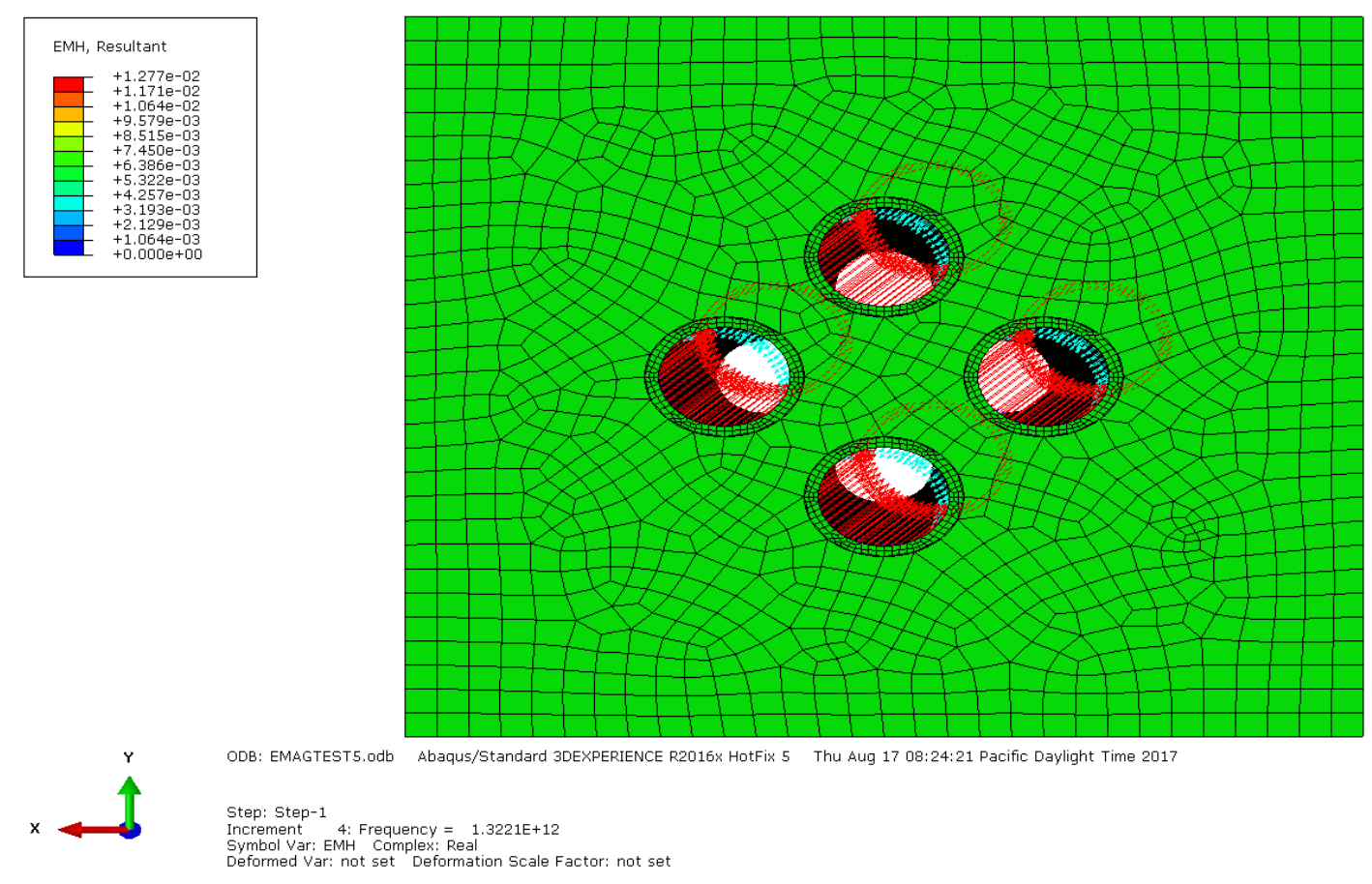

Figure 4.5.3

Variable EMH is Magnetic Field in $\mathrm{A} \mathrm{m}^{-1} \mathrm{E}+6$

(The EMH color scale only applies to vector arrows, not elements in the mesh)

\section{Results}

For Figures 4.1.1 - 4.5.2 the values shown in each element are magnitude or a value that does not include information about orientation. In the cases of Figures 4.3.1 and 4.4.1 where we are concerned only with the relative distribution of current, the orientation does not matter and therefore the polarity of NCURS is not of importance. NCURS fluctuates between positive and negative values with the Voltage for Models 3 and 4, but we are only concerned with the distribution in Figures 4.3.1 and 4.4.1. For Model 5 the magnetic field vector was shown in Figure 4.5.3 since we are interested in how the direction and magnitude of the magnetic fields influence each other.

Figure 4.1.1 shows a final temperature of $373.1 \mathrm{~K}$ and Figure 4.1.2 displays a maximum displacement of $0.619 \mathrm{~nm}$. Model 2 Figure 4.2.1 also shows a final temperature of $373.1 \mathrm{~K}$ and Figure 4.2.2 shows a maximum displacement of $0.006 \mathrm{~nm}$ (which is less than the thickness of the graphene sheet). These values are very small, however with a longer nanowire with better meshing capability, the discrepancy in displacement and the strain it causes will be much larger. 
This large difference in displacement is due to the lower CTE of CNTs, and clearly demonstrates that CNTs will have two orders of magnitude less displacement compared to their $\mathrm{Cu}$ counterparts, alleviating issues with extrusion. The steady state temperature reached $373.1 \mathrm{~K}$ was approximately equal to (due to rounding errors) what was set as the boundary condition (373.15 K), indicating that Joule heating is not accounted for.

We expect to see the current tend towards the circumference of the Cu nanowire (skin effect) in Model 3 Figure 4.3.1 and Figure 4.3.2, but the skin effect is not simulated. Figure 4.3.1 shows the current at each node in the mesh, which at first glance appears to be a result of the skin effect. However, there is high current density in the center and the current distribution is irregular, this is due to the distorted mesh. Since each element in the mesh on the cross section of the $\mathrm{Cu}$ has a different area, the displayed current varies from element to element. Figure 4.3.2 shows the current per unit area (ECD), which accounts for the surface area of each element. The ECD is identical everywhere in the model and is a more accurate representation of the current distribution. Looking at the ECD in model 3 reveals that the skin effect is not accounted for, as the current distribution would vary radially about the center of the cross section of $\mathrm{Cu}$. The skin depth for a given frequency is given by equation (2)

$$
\delta=\sqrt{\frac{\rho}{\pi \cdot f \cdot \mu_{r} \cdot \mu_{0}}}
$$

From Table 3.1 and equation (2) the skin depth of the Cu wire in Model 3 should be $65.2 \mathrm{~nm}$. The lack of skin effect in the model clearly indicates ABAQUS does not consider skin depth or the proper electromagnetic phenomenon that cause it. This has further implications that we cannot model the skin effect for a bundle of CNTs, which was one of the goals of this paper.

Model 4 shows no observable skin effect in a SWCNT bundle of 7, this is expected since there was no observable skin effect in the much larger wire in Model 3. The frequency was set to $100 \mathrm{PHz}$, which yields a skin depth of $0.53 \mathrm{~nm}$ from Table 3.3 and equation (2). This high frequency was chosen to reduce the skin depth to an extreme level which would reveal the skin effect in a bundle of $4 \mathrm{~nm}$ diameter SWCNTs. In Figure 4.4.1 the current distribution on each SWCNT appears uneven due to the distorted mesh, but the ECD in figure 4.4.2 is uniform showing that there is no skin effect. This is similar to Model 3 where there is high current at the locations where the mesh is coarser, but is revealed to be uniform when accounting for the mesh element area from ECD in figure 4.4.2. If the skin effect were to occur, we would expect 
Model 4 to show a lower concentration of current in the center SWCNT. Y. Feng and S. L. Burkett calculate that the skin effect in a $1 \mu \mathrm{m}$ diameter TSV of comprised of $4 \mathrm{~nm}$ diameter SWCNTs is expected to be very limited [12]. As the diameter of the SWCNTs increase, the calculated current density normalizes across the via, and the skin depth increases [12]. This contrasts with E. K. Farahani and R. Sarvari where they calculate and model a more apparent skin effect and skin depth in a $3 \mu \mathrm{m}$ bundle of Multi-Walled Carbon Nanotubes (MWCNT) in the $100 \mathrm{GHz}$ range [13]. The MWCNT bundles in [13] seem to be more subject to the skin effect than the SWCNT bundles in [12], however this could be due to the $3 \mu \mathrm{m}$ via diameter in [13] compared to the $1 \mu \mathrm{m}$ via diameter in [12] or differences in methodology.

Model 5 attempted to show that the magnetic fields due to AC current flow in CNTs should interact with each other and affect the current flow of other CNTs. However, ABAQUS does not allow for interactions in magnetic models and the resultant magnetic field vectors were independent to each CNT. Figure 4.5.1 shows the 3-D structure of the model mesh, with 4 4nm diameter SWCNTs surrounded by $\mathrm{Cu}$. Figure 4.5.2 shows that a positive magnetic field exists in the SWCNTs, but the magnitude of the magnetic field is zero everywhere in the $\mathrm{Cu}$ structure. This indicates that there are no electromagnetic interactions between structures in

ABAQUS. Figure 4.5 .3 shows the magnetic field vectors (as opposed to just the magnitude from Figure 4.5.2) which are identical in each SWCNT, and entirely absent in the Cu. In Figure 4.5.3 there is also no indication of electromagnetic interaction in the model.

\section{Conclusions:}

Models 1-5 indicate that ABAQUS is not ideal for modelling electromagnetic properties of CNTs. Skin effect is not simulated, and interactions do not occur between structures in the electromagnetic model. ABAQUS also does not consider ballistic transport or quantum effects such as kinetic inductance, which could affect the results. ABAQUS was designed for macroscopic mechanical modelling, and quantum effects are not calculated. While ABAQUS is not well suited for electromagnetic analyses, it is designed for use in thermal and mechanical analyses and could be helpful in determining the maximum temperature the CNT-Cu composite can handle before the difference in CTE causes adhesive failure. External temperature would be the main factor for mechanical failure since Joule heating is not accounted for. 
It is recommended that an adhesive model should be run in the future by moving forward with the data from tables 6.1 and 6.2, investigating how the surface energies affect the mechanical strength of a Cu-CNT bond under thermal stress. The force required to separate two surfaces is related to the sum of their surface energies [10]. T. Sapanathan et al. completed a study relating the shear force required to break an Aluminum-Copper interface, and the cohesive modelling parameters in Abaqus, "The cohesive region was assigned with material properties (dimensionless ratios of $\mathrm{E} / \mathrm{Knn}, \mathrm{G} 1 / \mathrm{Kss}$ and $\mathrm{G} 2 / \mathrm{Ktt}$ )... this model can be used only to capture the experimental stiffness results using an inverse calibration of interface stiffness" [14]. They found that by linearly changing these parameters in their simulation that they could closely model the force required to break the interface from their real-world tests. According to the Abaqus Analysis User's Guide, "The modeling of bonded interfaces in composite materials often involves situations where the intermediate glue material is very thin and for all practical purposes may be considered to be of zero thickness" [11]. This indicates that the Cohesive interaction could be used to represent Adhesion between two solids. From the Surface Energies in Table 6.1 we can assume parameters for the cohesive material in Table 6.2. It would be more advantageous to use the cohesive interaction model for zero thickness, rather than using a cohesive element with finite thickness. However, the cohesive interaction uses the parameters $\mathrm{Knn}, \mathrm{Kss}$, and Ktt rather than the ratios used in the cohesive material. Another option would be to use the Damage interaction to specify the normal and shear stresses required to break the contact.

\begin{tabular}{|l|r|l|}
\hline Element & $\begin{array}{l}\text { Surface energies } \\
\text { (mJ/m^2) }\end{array}$ & Reference \\
\hline Copper & 1650 & {$[15]$} \\
\hline Graphene & 46.7 & {$[16]$} \\
\hline Al & 1650 & Estimated \\
\hline \multicolumn{3}{|c|}{} \\
\hline $\begin{array}{l}\text { Cu/CNT to Cu/Al Surface } \\
\text { Energy ratio }\end{array}$ & 0.514 & Calculated \\
\hline
\end{tabular}

Table 6.1 Surface Energies of Materials 


\begin{tabular}{|l|l|r|}
\hline Adhered Solids & Cohesive Parameter & Value \\
\hline \multirow{4}{*}{ Cu/AI [14] } & E/Knn & 600 \\
\cline { 2 - 3 } & G1/Kss & 150 \\
\cline { 2 - 3 } & G2/Ktt & 150 \\
\hline \multirow{3}{*}{$\begin{array}{l}\text { Cu/CNT } \\
\text { (Estimated) }\end{array}$} & E/Knn & 308 \\
\cline { 2 - 3 } & G1/Kss & 77 \\
\cline { 2 - 3 } & G2/Ktt & 77 \\
\hline
\end{tabular}

Table 6.2 Cohesive Parameters

\section{Acknowledgements:}

Thank you to Dr. James Morris who provided guidance and resources for this paper.

Thanks to Portland State University and Dassault Systemes SIMULIA Corporation for providing the ABAQUS 6.16 Teaching License to use for simulations. Figure 4.1.1 - Figure 4.5.3 were created with ABAQUS software. 


\section{References:}

[1] “Mechanical integrity of a carbon nanotube/copper-based through-silicon via for 3D integrated circuits: a multi-scale modeling approach - IOPscience." [Online]. Available: http://iopscience.iop.org.proxy.lib.pdx.edu/article/10.1088/0957-4484/26/48/485705/meta. [Accessed: 13-Jul-2017].

[2] S. Sun et al., "Vertically aligned CNT-Cu nano-composite material for stacked throughsilicon-via interconnects," Nanotechnology, vol. 27, no. 33, p. 335705, 2016.

[3] T. Xu, Z. Wang, J. Miao, X. Chen, and C. M. Tan, "Aligned carbon nanotubes for throughwafer interconnects," Applied Physics Letters, vol. 91, no. 4, p. 42108, 2007.

[4] A. Maffucci, "Carbon Interconnects" Department of Electrical and Information Engineering, University of Cassino and Southern Lazio. August 2017.

[5] D. Gall, "Electron mean free path in elemental metals," Journal of Applied Physics, vol. 119, no. 8, p. 085101, Feb. 2016.

[6] Z. H. Ni et al., "Graphene Thickness Determination Using Reflection and Contrast Spectroscopy," Nano Lett., vol. 7, no. 9, pp. 2758-2763, Sep. 2007.

[7] “Carbon nanotube," Wikipedia. 09-Aug-2017.

[8] J. Hone et al., "Thermal properties of carbon nanotubes and nanotube-based materials," Appl Phys A, vol. 74, no. 3, pp. 339-343, Mar. 2002.

[9] C. Subramaniam et al., "One hundred fold increase in current carrying capacity in a carbon nanotube-copper composite," Nature Communications, vol. 4, p. ncomms3202, Jul. 2013.

[10] K. Kendall, "The adhesion and surface energy of elastic solids," J. Phys. D: Appl. Phys., vol. 4, no. 8, p. 1186, 1971. 
[11] Abaqus Analysis User's Guide 6.14

[12] Y. Feng and S. L. Burkett, "Modeling a copper/carbon nanotube composite for applications in electronic packaging," Computational Materials Science, vol. 97, pp. 1-5, Feb. 2015.

[13] E. K. Farahani and R. Sarvari, "Anomaly in current distribution of multiwall carbon nanotube bundles at high frequencies," in 14th IEEE International Conference on Nanotechnology, 2014, pp. 702-705.

[14] T. Sapanathan, R. Ibrahim, S. Khoddam, and S. H. Zahiri, "Shear blanking test of a mechanically bonded aluminum/copper composite using experimental and numerical methods," Materials Science and Engineering: A, vol. 623, pp. 153-164, Jan. 2015.

[15] "Surface energy," Wikipedia. 20-Jun-2017.

[16] S. Wang, Y. Zhang, N. Abidi, and L. Cabrales, "Wettability and Surface Free Energy of Graphene Films," Langmuir, vol. 25, no. 18, pp. 11078-11081, Sep. 2009. 


\section{Appendices}

\section{Appendix A}

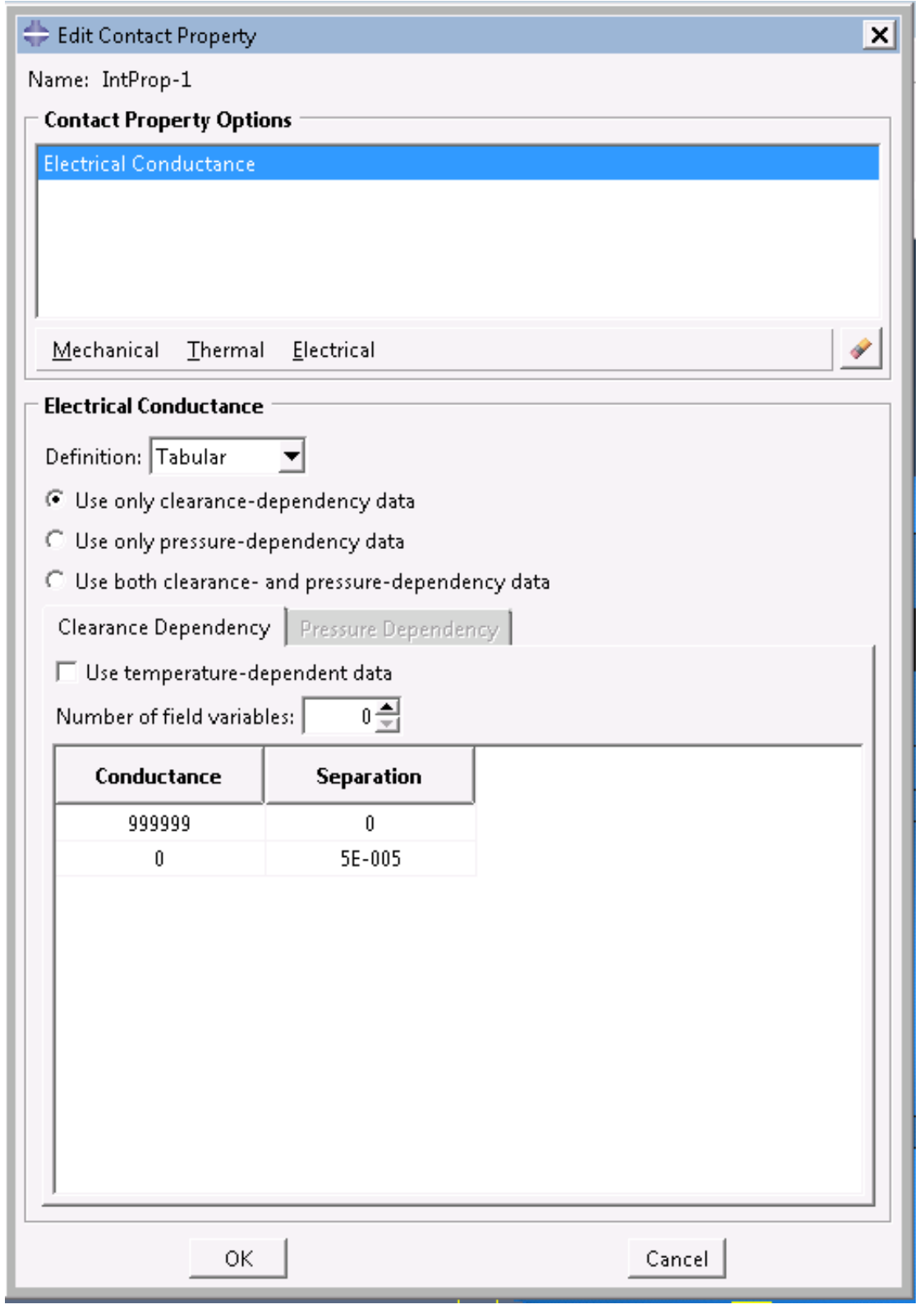

Figure 8.1 Contact Properties 


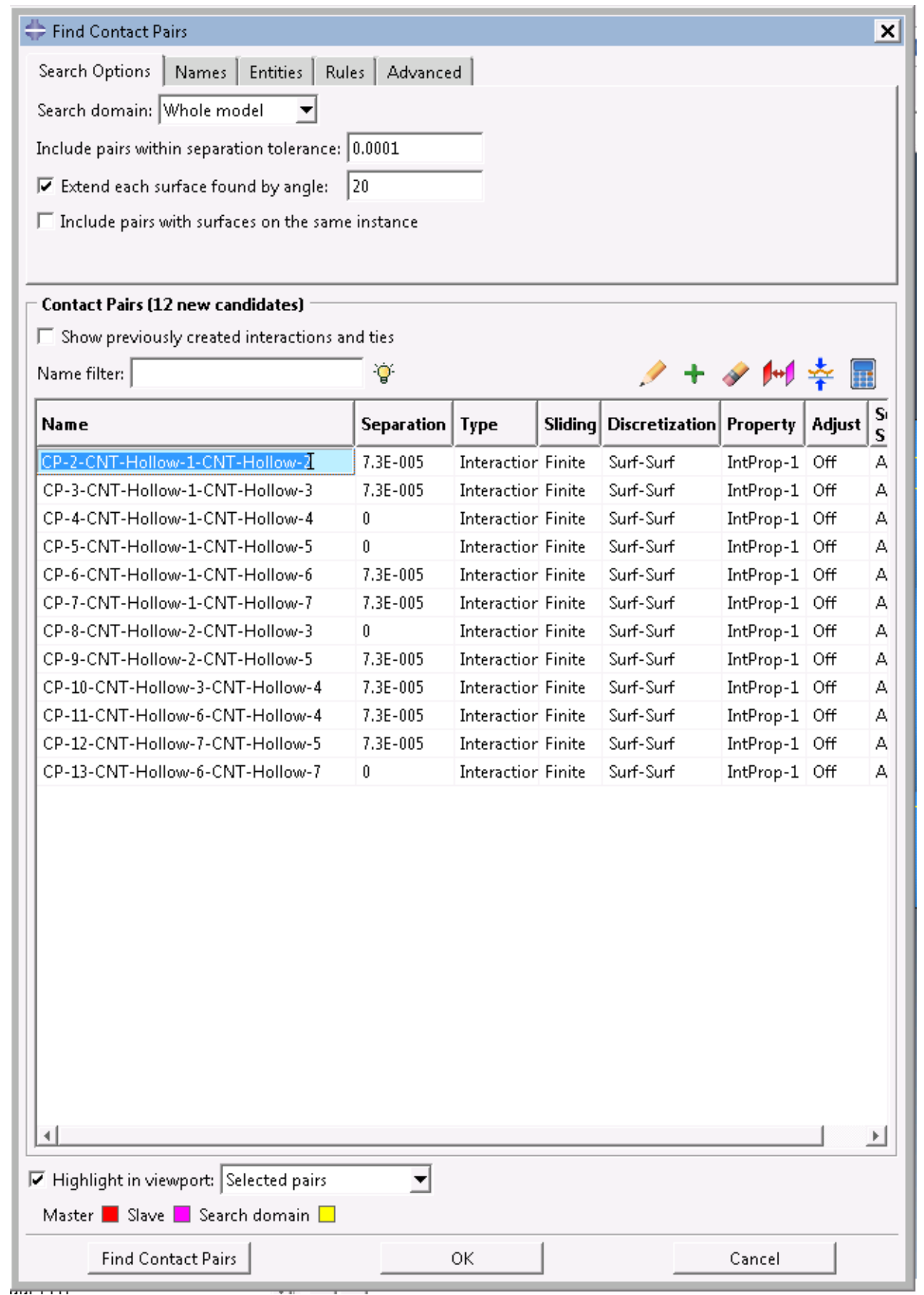

Figure 8.2 Contact Pairs and Separation

When creating a contact between two materials in ABAQUS (Figure 8.2), an interaction property must first be defined (Figure 8.1). For Model 4, the conductance between neighboring SWCNTs was assumed to be very high to allow current to flow between the SWCNTs. The values in Figure 8.1 were chosen such that the resistance between SWCNTs is negligible compared to material resistivity at their furthest separation of $0.073 \mathrm{~nm}$ given in Figure 8.2. Conductance in an interaction must be defined in terms of distance of separation of materials. Given two values 
of conductance with respective separation, ABAQUS will linearly interpolate the conductivity between any two contact pairs with the interaction property. In Figure 8.2 where interfaces are separated by $0.073 \mathrm{~nm}$, the conductivity is determined to be $460 \mathrm{E}+3$ Siemens $(2.17 \mu \Omega$ of resistance). Where there is $0 \mathrm{~nm}$ separation the conductivity is $1 \mathrm{E}+6$ Siemens ( $1 \mu \Omega$ of resistance). This was done to assume near-ideal contacts at the interfaces to neglect contact resistances that may interfere with the skin effect. 